\section{Use Of Modern Information And Communication Technologies In The Learning Process}

\author{
Umarova Fotima Abdurahimovna,
}

Doctoral Student, Tashkent State Pedagogical University Named After Nizami, Uzbekistan

\begin{abstract}
G OPEN ACCESS
The American Journal of Social Science And Education Innovations JULY 2020

Page No.: 246-255

Volume-II Issue-VII

PUBLISHED: 30 JULY 2020 www.usajournalshub.com/inde x.php/tajssei

Copyright: Original content from this work may be used under the terms of the Creative Commons Attribution 4.0 licence.
\end{abstract}

\title{
Abstract
}

This article discusses in detail how to achieve the effectiveness of learning through the use of computer technology in the education system, how to facilitate the organization of the educational process, as well as how to increase and strengthen participants' interest in the lessons. The article describes in detail the meaning, purpose, content, methods, means of teaching ICT in the activities of educational institutions.

Keywords: Interactive boards, programs, motivational aspect, content aspect, educational and methodological aspect, organizational aspect, control and evaluation aspect, audio and video textbooks, online lessons (site), multimedia electronic textbooks.

\section{Introduction}

Teaching in pedagogy is a purposeful pedagogical process of organizing and stimulating active educational and cognitive activities of students to master knowledge, skills, skills, development of creative abilities and moral ethical views. Teaching is a type of educational activity in which the quantity and quality of elements of knowledge and skills of the 
student are brought to the proper level (average, reference, possible), which is the goal of learning. [1]

The rapid development of digital technologies in the modern world requires pedagogy to keep up with trends. [2]

It is no secret that in today's market economy, the development of our society requires new technologies, including new information and communication technologies. In particular, the widespread introduction of multimedia and web technologies, the intensive study of computer-created graphics, animation and video technologies require computer literacy. In recent years, Uzbekistan has taken a number of measures to develop computerization and information and communication technologies (ICT). [3]

The main principles of the use of information and communication technologies (ICT) are the development of students' motivation to acquire knowledge, an individual approach to students, simplicity and ease of creation and use, directionality on the integration of academic disciplines.

\section{The Main Findings And Results}

It is known that in the exchange of information, the information received by the human visual sense organ is most effectively received, and it leaves a deep mark on the memory. In particular, the information provided by voice has a positive effect. The least effective medium is written information, which takes more time to receive and process in the brain, and due to the physiology of each person, a certain amount of information is lost and stored in memory. The least effective medium is written information, which takes more time to receive and process in the brain, and due to the physiology of each person, a certain amount of information is lost and stored in memory. [4]

The largest amount of information, about $90 \%$, a person receives with the help of sight, about $9 \%$ - with the help of his hearing and only $1 \%$ with the help of other senses. Information received by a person in the form of visual, auditory and other perceptual channels is stored in his memory.[5]

In the process of development of the education system, the tasks of the content of education change, the forms of organization of education also change, they are variable: 
some become obsolete, instead of which new forms appear. But this does not mean that the lesson as a form of teaching has not changed throughout the entire time. On the contrary, the present stage of development of education (training) is characterized by the renewal of the content of teaching methods. The share of creative work in the composition and professional activity of a teacher who is engaged in the design of educational material and the educational process is significantly increasing. Therefore, even today the question is relevant: "What is needed in order to conduct an effective, interesting lesson for students?" A. Disterweg said: " "Bad teacher presents the truth good - teaches her to find". [6]

The use of ICT plays a positive role in modern learning. Today, ICT can be considered the latest way to transfer knowledge, which corresponds to a qualitatively new content of learning and development of the student. This method allows the child to learn with interest, look for sources of information, and also educates independence and responsibility in obtaining new knowledge.

Information and communication technologies (ICT) are "a wide range of digital technologies used for the creation, transmission and dissemination of information and services (computer equipment, software, telephone lines, cellular communications, e-mail, cellular and satellite technologies, wireless and cable networks, multimedia, and the Internet)".[7]

ICT is a collection of technologies that simultaneously use several information environments: graphics, text, video, photography, animation, sound effects, high-quality sound. [8]

To diversify the lesson, try to make it quite interesting, extraordinary, accessible and meaningful, the teacher should include ICT in the planning at any of the stages of the lesson, both for checking homework and for introducing new material, fixing the topic, monitoring the assimilation of the studied, summarizing and systematizing the topics completed.

ICT is a mastery of skills in an integrated multimedia environment, implementing the further development of the idea of associatively related information received, processed and presented in various forms, taking into account the psychological - 
pedagogical foundations of the use of ICT tools in the educational process. [9]

One such skill is professional ICT competence. Thus, the use of ICT in teaching greatly increases not only the effectiveness of training, but also helps to improve various forms and methods of training, and increases interest in in in-depth study of the material. Modern ICTs provide additional opportunities for the formation and development of information competence. Their application depends on the ability to incorporate ICT into the educational system, on the professional competence of the teacher, creating positive motivation and psychological comfort, contributing to the development of skills and skills.

Information and communication technologies increasingly penetrate the various spheres of modern society: business, finance, the media, science and education. "The possibilities of a person today are determined not by where he lives, but by what education he received. It is necessary that not only schools, but also universities be focused on the Internet. The use of modern ICT in professional activities determines its competitiveness. " The emergence of information technologies is associated with the following achievements: the emergence of new means of information accumulation, the development of communication means, the possibility of automated processing of information using a computer.

ICT can be classified by its functional application. A.V. Dvoretskaya identifies the following types of information technologies: presentations, educational games and developing programs, didactic materials, programs - simulators, virtual experiment systems, electronic textbooks, electronic encyclopedias.

Interactive boards are a touch screen connected to a computer, the image from which is transmitted to the board by a projector. Together, they are an interactive complex.

Programs - simulators perform the function of didactic materials. Modern programs simulators can track the progress of the decision and report errors.

Electronic textbooks and training courses combine all or several training programs into a single software package.[10]

When working with these sources of information, the teacher needs to pay attention to the reliability of the information found and need to adapt the material to different levels 
of learning of students.

ICT educational tools can be classified according to a number of parameters:

1. By solved pedagogical tasks:

- facilities, providing basic training (electronic textbooks, training systems, knowledge control systems;

- facilities practical training (problem books, workshops, virtual constructors, programs imitation modeling, simulators);

- auxiliary means (encyclopedias, dictionaries, reading books, developing computer games, multimedia training sessions);

- complex means (remote).

2. By functions in the organization of the educational process:

- information and educational (electronic libraries, electronic books, electronic periodicals, dictionaries, reference books, educational computer programs, information systems);

- interactive (email, electronic teleconferencing);

- search engines (directories, search engines).

3. By information type:

- electronic and information resources with textual information (textbooks, study guides, problem books, tests, dictionaries, reference books, encyclopedias, periodicals, numerical data, program and educational materials);

- electronic and information resources with visual information (collections: photographs, portraits, illustrations, video fragments of processes and phenomena, demonstrations of experiments, video tours; statistical and dynamic models, interactive models; symbolic objects: diagrams, diagrams);

- electronic and information resources with audio information (sound recordings of poems, didactic speech material, musical works, sounds of animate and inanimate nature, synchronized audio objects);

- electronic and information resources with audio and video information (audio and video objects of animate and inanimate nature, subject excursions);

- electronic and information resources with combined information (textbooks, study 
guides, primary sources, anthologies, problem books, encyclopedias, dictionaries, periodicals). [10]

4. By forms of ICT application in the educational process:

- lesson;

- extracurricular

5. By the form of interaction with the student:

- asynchronous communication mode technology - "offline";

- synchronous communication technology - "online".

There are several aspects of the use of various educational ICT tools in the educational process:

1. Motivational aspect. Appling of ICT contributes to an increase in interest and the formation of positive motivation of students, since conditions are created:

- maximum consideration of individual educational opportunities and needs of students;

- a wide choice of content, forms, rates and levels of training sessions;

- disclosing the creative potential of students;

- mastering by students of modern information technologies.

2. Content aspect. ICT capabilities can be used:

- when building interactive tables, posters and other digital educational resources on certain topics and sections of the academic discipline;

- for the creation of individual test mini-lessons;

- for the creation of interactive homework assignments and simulators for independent work of students.

3. Educational and methodological aspect. Electronic and information resources can be used as educational and methodological support of the educational process. The teacher can use various educational ICT tools in preparation for the lesson; directly when explaining new material, to consolidate the acquired knowledge, in the process of quality control of knowledge; for the organization of independent study of additional material by students, etc. Computer online tests and test tasks can be used to implement various types of control and assessment of knowledge. 
In addition, the teacher can use a variety of electronic and information resources in the design of educational and extracurricular activities.

4. Organizational aspect. ICT can be used in various options for organizing training:

- when teaching each student according to an individual program based on an individual plan;

- at frontal or subgroup forms of work.

5. Control and evaluation aspect. The means of monitoring and assessing the educational results of students using information and communication technologies are tests and test items that allow for various types of control: input, intermediate and final.

Tests can be conducted online (carried out on a computer in an interactive mode, the result is automatically assessed by the automatic system) and offline (the teacher evaluates the results with comments, work on errors). Thus, the use of ICT in teaching any subject significantly increases not only the effectiveness of learning, but also helps to improve various forms and methods of teaching, increases the interest of students in deep study of the educational material.

In the modern world, it is required that every teacher can prepare and conduct a lesson using information and communication technologies, and the use of information and communication technologies in the educational process is one of the ways to increase the motivation of learning. Information and communication technologies contribute to the development of the creative personality of not only the student, but also the teacher himself, the use of such technologies contributes to the realization of the main human needs - communication, education.

In general, the emergence of information and communication technologies is associated with the emergence of modern means of storing information, the development of communication means, the ability to process information using a computer. For the effective use of ICT, it is necessary that these technologies are available to both teachers and students. Providing access for both parties will significantly improve the quality of student achievement.[9]

The use of information and communication technologies is not the influence of fashion, but a necessity dictated by the current level of education development. 
It is known that the most effective way of teaching is visual demonstration and synchronous explanation of the material being studied. Classical and integrated lessons, accompanied by multimedia presentations, online tests and software products, allow students to deepen the knowledge gained earlier, as the English proverb says - "I heard and forgot, I saw - and remembered". The use of animation in slides allows the educator to give students a more vivid idea of what they heard in the lesson. Students are happy to immerse themselves in the lesson material. An increase in motivation and cognitive activity is achieved due to a variety of forms of work, the possibility of including a game moment: if you solve the examples correctly - open the picture, insert all the letters correctly - you will move the fairytale hero closer to the goal. The computer gives the teacher new opportunities, allowing, together with the students, to enjoy the fascinating process of learning, not only pushing the walls of the classroom with the power of imagination, but with the help of the latest technologies allows you to immerse yourself in a bright colorful world. Such a lesson causes an emotional uplift in children, even students with poor academic performance willingly work with a computer. The computer does not replace live communication with the teacher and other sources of information, however, taking into account the interests of students, it increases interest in studying any discipline.

One of the advantages of using information and communication technologies in teaching is improving the quality of education due to the novelty of activities, interest in working with computers. The use of information and communication technology in the classroom significantly increases its effectiveness, speeds up the preparation process for the lesson, allows the teacher to fully demonstrate his creativity, provides clarity, attracts a large amount of didactic material, increases the volume of work performed in the lesson by $1.5-2$ times.

The use of information and communication technologies opens up didactic opportunities related to the visualization of material, its "revitalization", the ability to make visual travels, the ability to visualize those phenomena that cannot be demonstrated in other ways, allow you to combine control and training procedures. "The golden rule of didactics is visualization" (Yan Kamensky). Multimedia systems make it possible to make 
the presentation of didactic material as convenient and visual as possible, which stimulates interest in learning and allows you to eliminate gaps in knowledge.[7]

\section{Conclusion}

In conclusion, the use of modern technologies in the learning process allows teachers to achieve a high quality of academic performance, motivation rises, the number of students taking part in olympiads, research projects and various creative competitions increases, and, accordingly, the level of knowledge rises.

Thus, the use of new technologies in teaching contributes to the development of students' cognitive activity, oeuvre, creativity, the ability to work with information, increase self-esteem, and most importantly, the dynamics of the quality of academic performance increases.

The use of a computer in the educational process - (the introduction of new information technologies) is an attempt to offer one of the ways that can intensify the educational process, optimize it, raise the interest of studentes in studying the subject, implement the ideas of developing education, increase the pace of the lesson, and increase the volume of independent work. Promotes the development of logical thinking, a culture of mental work, the formation of skills for independent work, and also has a significant impact on the motivational sphere of the educational process.

\section{References}

1. Afanasyeva OV The use of ICT in the educational process. 2012. URL: http://pedsovet.org

2. Umarov Kh.A., Umarova Z.A. "Use of electronic educational resources in order to create an educational ecosystem." Advanced Information Technologies (PIT 2018) [Electronic resource]: proceedings of the International Scientific and Technical Conference, Samara: Publishing House of the Samara Scientific Center of the Russian Academy of Sciences, 2018

3. Umarova F.A., Umarova Z.A., Umarov Kh.A. "Scientific and practical bases of creation and use of electronic educational resources in the educational process." 
European Journal of Research and Reflection in Educational Sciences Vol.7 no. 12,2019. ISSN 2056-5852

4. Umarova F.A. The role of ICT in achieving effectiveness in education./ Innovative development of education science. / international scientific and practical conference / July 2020 Kazakhstan.

5. Petukhova E.I. Information technologies in education / Successes of modern natural science / M., $2013 .--39$ p.

6. Krutetsky, V.A. Psychology: a textbook for students of secondary educational institutions. - M., 1980.-357 p.

7. The use of modern information and communication technologies in the educational process: teaching aid / Authors: D.P. Tevs, V.N. Podkovyrova, E.I. Apolskikh, M.V., Afonina. - Barnaul: BSPU, 2006.-59 p.

8. Grigoriev S.G., Grinshkun V.V. Informatization of education, Textbook. - Moscow, 2005 .-- $181 \mathrm{p}$.

9. Korotkova M.V. Personality-oriented approach in the use of visual aids in history lessons / M.V. Korotkova // Teaching history at school. - 2008. - No. 1. - 83 p.

10. Komarova, I. The use of information technology in improving the education system / I. Komarova. // Public education. - 2006. - No. 2. - 159 p. 